\title{
Cross-cultural adaptation of Chronic Pain Coping Inventory - Brazilian version
}

\author{
Adaptação transcultural do Chronic Pain Coping Inventory - versão brasileira
}

Layz Alves Ferreira Souza', Diná de Almeida Lopes Monteiro da Cruz², Lilian Varanda Pereira ${ }^{1}$

DOI 10.5935/2595-0118.20180020

\section{ABSTRACT}

BACKGROUND AND OBJECTIVES: The Chronic Pain Coping Inventory is a widely used instrument to evaluate pain coping, however, there are no Brazilian publications about this tool. The objective of the study was to adapt the Chronic Pain Coping Inventory to the Brazilian culture.

METHODS: According to the international guidelines for cross-cultural adaptation of measurement instruments, the study was developed in the stages: planning, translation, synthesis, analysis by an expert committee, back-translation, evaluation by the original author, discussion with lay people, pre-test and final evaluation.

RESULTS: A pre-test of the consensus version approved by the committee was conducted with 59 people, resulting in the Brazilian Version of the Chronic Pain Coping Inventory adapted according to the Brazilian culture. A preliminary reliability analysis showed adequate values for the subscale of protection, ask for help, seek social support, coping self-statements and exercise/ stretch. Its use in clinical practice and research shows a promising future towards a multidisciplinary pain management in Brazil.

CONCLUSION: Future research is needed to determine the psychometric properties of the Brazilian version of the Chronic Pain Coping Inventory and to confirm the need to include items related to religious practices, and the use of pharmacological methods and complementary therapies as coping strategies for chronic pain.

Keywords: Adaptation psychological, Chronic pain, Pain management, Translation.

\section{RESUMO}

JUSTIFICATIVA E OBJETIVOS: O Chronic Pain Coping Inventory trata-se de um instrumento largamente utilizado para a avaliação do enfrentamento de dor, no entanto, ainda náo há publicaçóes brasileiras sobre essa ferramenta. O objetivo deste estudo foi adaptar o Chronic Pain Coping Inventory para a cultura brasileira.

MÉTODOS: De acordo com as diretrizes internacionais para a adaptação transcultural de instrumentos de medida, o estudo foi desenvolvido nas etapas: planejamento, tradução, síntese, análise por comitê de especialistas, retrotradução, avaliação pelo autor original, discussão com leigos, pré-teste e avaliação final.

RESULTADOS: Foi realizado o pré-teste da versão consensual aprovada pelo comitê em 59 pessoas, obtendo-se ao final o Chronic Pain Coping Inventory - Versão Brasileira adaptado conforme as nuances da cultura no Brasil. Análise preliminar da fidedignidade mostraram valores adequados para a subescala de proteção, pedido por ajuda, busca por suporte social, autoafirmaçóes de enfrentamento e exercícios/alongamento. Seu uso na prática clínica e de pesquisa aponta futuro promissor para o avanço no manejo multidisciplinar da dor no Brasil.

CONCLUSÁO: Pesquisas futuras são necessárias para determinar as propriedades psicométricas do Chronic Pain Coping Inventory - Versão Brasileira e confirmar a necessidade de inclusão de itens relacionados às práticas religiosas, e ao uso de métodos farmacológicos e terapias complementares como estratégias de enfrentamento da dor crônica.

Descritores: Adaptação psicológica, Dor crônica, Mensuração da dor, Tradução.

\section{INTRODUCTION}

People with chronic pain (CP), a multidimensional phenomenon, may use different coping strategies (CS). Coping with a stressor, such as pain, means undertaking cognitive and behavioral efforts to deal with internal or external demands that arise from stress and are assessed by the person as something that exceeds their personal resources ${ }^{1}$.

A systematic literature review published in $2015^{2}$ identified 23 instruments to measure coping. Five of which were specific for the assessment of pain coping, the Vanderbilt Pain Management Inventory (VPMI) ${ }^{3}$, the Pain Coping Questionnaire $(\mathrm{PCQ})^{4}$, Pain Coping Inventory (PCI) ${ }^{5}$, Coping Strategies Questionnaire $(\mathrm{CSQ})^{6,7}$ and the Chronic Pain Coping Inventory (CPCI). Until the beginning of the first half of 2018, a literature search did not identify new publications of pain coping measurement instruments. 
The VPMI has not been cross-culturally adapted to Brazil. Although it has already been widely used, it has fallen into disuse due to its dualistic perspective that focuses only on active (adaptive) and passive (non-adaptive) ${ }^{3}$ coping, making the coping assessment unfeasible in different contexts where the same strategy could be considered adaptive and in others non-adaptive ${ }^{2}$.

The PCQ and PCI also have no Brazilian version. The first is a specific instrument for the assessment of pain coping in a population of children and adolescents $s^{4}$, and the second one does not have a long recommendation for use because the authors do not present a consistent theory for the pain coping measurement ${ }^{5}$. The CSQ is the only instrument for assessment of pain coping translated into Brazilian Portuguese ${ }^{7}$. However, the methodological process used in its cross-cultural adaptation is not clear about the compliance with the guidelines on the topic ${ }^{8-10}$ and, to the best of our knowledge, there are no publications dealing with its psychometric properties in Brazil. Also, in the theory underlying the CSQ, there is some confusion of the coping measurement with catastrophizing, which does not reflect the coping itself. Although catastrophizing is an important predictor of psychological and physical dysfunction, it is not a personal effort to manipulate the stress, being considered a distortion of the thought by the cognitive-behavioral theory ${ }^{11,12}$.

The CPCI was developed in the United States based on a critical literature review on coping theory and studies that used other instruments, especially the VPMI and CSQ ${ }^{12,13}$. The need for another instrument to measure coping in people with pain arose with the intention of overcoming the limitations identified in the other instruments ${ }^{12}$. The theory behind this instrument was published in 1991, four years before its publication ${ }^{12}$.

A review of the literature published in February 2018 in the Pubmed, SCOPUS, Web of Science and PsycINFO databases showed that CPCI has already been cross-culturally adapted and validated for populations in Canada (French language) and France $^{14,15}$, Canada (English language) ${ }^{16,17}, S_{w e d e n}{ }^{18}, \operatorname{Spain}^{19}$, China $^{20-22}$, North Korea ${ }^{23}$, Portugal ${ }^{24}$, Italy ${ }^{25}$ and Poland ${ }^{26}$. In these studies, the samples were from adult and elderly populations, with ages ranging from 32.5 to 82.0 years old, with CP in several body regions (lumbar, lumbopelvic, generalized pain, as in fibromyalgia), in outpatient or inpatient care.

The initial version of the CPCI, published in 1995, had 64 items that assessed the use of cognitive and behavioral $\mathrm{CS}^{13}$ but a review in 2001 excluded the "Medication use" scale and included the "Rhythm regulation" scale, totaling 70 items. The copyright was transferred to a health testing company, Psychological Assessment Resources (PAR) ${ }^{27}$.

The CPCI consists of nine subscales distributed in two domains, being the CS focused on the disease and the CS focused on well-being. The first consists of protection subscales (restriction on the use or movement of some part of the body), rest (lay, sit, or going to a dark or quiet place due to pain) and asking for help (asking for help in some activity when you are in pain, as in housework or to get something). In the CS domain focused on well-being, there are the subscales of search for social support (talking or spending time with a friend or loved one when experiencing pain - the subject of the conversation can be about pain or not); coping self-statements (intentional positive thoughts that inspire hope); rhythm regulation (change in rhythm of activities, such as doing activities more slowly, taking breaks, or maintaining a rhythm different from what was accustomed); exercise/stretching (commitment to some activity for muscle strengthening or stretching), relaxation (use of strategies to relax as meditation, listening to music, progressive muscle relaxation, diaphragmatic breathing, mental images, hypnosis, among others); and persistence in tasks (tendency to continue activities normally despite pain) ${ }^{27}$.

The CPCI can be used by physicians, nurses, psychologists, or other health professionals to track the CS used before treatment, to assess the clinical course and effectiveness in the post-treatment, the course of the painful experience, the suffering generated by pain, and the documentation of treatment progress. This instrument was developed to measure strategies that men or women, between 20 and 80 years old, use to cope with their pain $^{13,27}$.

The literature review showed that CPCI has not yet been cross-culturally adapted into the Portuguese language spoken in Brazil. However, this gap can be filled by the process of adaptation to the language, culture, context and lifestyle ${ }^{10}$ in Brazil, making possible the production of an instrument equivalent to the original for use in our culture ${ }^{8}$.

Therefore, this research aimed to perform the cross-cultural adaptation of CPCI for the assessment of chronic pain coping among Brazilians.

\section{METHODS}

It is a methodological study, of cross-cultural adaptation of a CP coping assessment instrument, the CPCI.

The process of cross-cultural adaptation was performed between August 2015 and October 2016 guided by guidelines described in the literature ${ }^{10,28}$. The order of accomplishment of some methodological steps was adapted, like the pre-test (PT) that was performed by three times in order to obtain better equivalence between the original instrument and the Brazilian one, and the back-translation that was performed only after the conclusion of two pre-tests ${ }^{29}$. The following steps were:

\section{Planning}

It involved the request and authorization of the PAR company for the cross-cultural adaptation of CPCI to the Brazilian population, research on the concepts of coping with pain and its nuances in Brazilian culture, reading the professional's manual ${ }^{27}$ regarding its use, and selection and invitation of experts to form the CPCI cross-cultural adaptation assessment committee.

In order to investigate the concepts of coping and their representation to the Brazilian culture, a search was made in the Virtual Health Library (VHL), Google Academic, without restriction of dates (until February 2018), with a filter for national literature, using the descriptors ("enfrentamento" OR "coping") AND ("dor" OR "pain") as well as cross-referenced search in books on the topic. 


\section{Translation}

It was performed by two independent translators (T1 and T2), bilingual and fluent in Brazilian Portuguese and English, with the mother tongue being Portuguese. The translator who lived at least one year in the United States of America, but whose permanent residence at the time of the translation was in $\mathrm{Brazil}^{30}$, was considered fluent. The T1 was a bachelor's degree in letters (English) and the T2 a professional translator specialized in academic works of the health area, both lay people for the CPCI.

\section{Synthesis or reconciliation}

The two translators and the researchers synthesized, in consensus, the two translations (T1 and T2), generating a single document the Consensual Translation (CT). The deadlocks for the synthesis were solved by the researchers and translators by consulting the dictionaries of the Portuguese language Aurélio and Michaelis, in order to choose the translated term that best defined the investigated construct and that was popularly used in Brazilian culture. In cases where none of the translations were chosen, the sentence was reformulated according to the authors' understanding, using synonyms for words as proposed in dictionaries. The CT was tabulated alongside the original English version and the T1 and T2 versions. The CT was then submitted for equivalence analysis by an expert committee.

\section{Analysis by an expert committee}

The committee consisted of seven experts. Four of them were bilingual professionals (a Ph.D. in psychology expert in human behavior, a physician expert in rheumatology with expertise in pain, a MSc in linguistics, expert in the translation of scientific articles in the area of health and a nurse, a Ph.D. with expertise in health measurement of subjective phenomena), three researchers (a Ph.D. in nursing with expertise in health measurement of subjective phenomena, a MSc and a Ph.D. in nursing with expertise in pain) also participated.

Experts assessed CT for conceptual, semantic, idiomatic and cultural equivalence, and assessed the results of the pre-test (PT). In the assessment of equivalences, the following concepts were considered ${ }^{31}$ : - Conceptual equivalence: referring to the capacity to transfer meaning from the concepts of the original instrument to the adapted version to ensure the similar effects on the respondents of the two cultures;

- Semantic equivalence: maintenance of the meanings of the original instrument and of the translated to the target language, so that the translation has a representation of the construct involved;

- Idiomatic equivalence: substitution of popular expressions and colloquial terms from the original culture to others that are equivalent in the target culture;

- Cultural equivalence: coherence between expressions of the translated instrument and the original, considering the reality of each cultural context.

The assessment was performed through item-objective congruence $^{32}$, and the item judged as equivalent received the value " +1 "; in the indecision on equivalence the value was zero " 0 "; and in the absence of equivalence, " 1 ". For this assessment, an instrument prepared for this purpose was used. The items with $75.0 \%$ or greater agreement among the experts were retained ${ }^{32}$. The others, where pertinent and in accordance with the theory of coping with pain, were modified after discussions among the researchers. As a result of this process, we obtained the Brazilian version 1.0 of the CPCI.

\section{Back translation}

Two translators independently performed the back translation of the CPCI Brazilian version 1.0 (RT1 and RT2). They were bilingual, fluent in Portuguese and English, and had as their mother tongue English, as well as being covert in relation to the CPCI and the subject studied. The work of the retro-translators was remunerated.

\section{Assessment by Psychological Assessment Resources and the original author}

Both back translations and CPCI - Brazilian version 1.0 were sent to PAR, which mediated contact with the original author. After discussion, the instrument underwent some changes, resulting in the Brazilian version 1.1 of the CPCI.

\section{Discussion with lay people}

A meeting was held between researchers and two lay people, one Brazilian bilingual and one American with basic knowledge of Portuguese. The first resided in Brazil and the second in the United States, but on a visit to Brazil. The purpose of this meeting was to clarify the cultural representation of each item for the American to seek the equivalent representation for the Brazilian. At that time, the terms used in the CPCI version - Brazilian version 1.1 were discussed, and the lay people made suggestions for adaptations, generating the Brazilian Version 1.2 of the CPCI.

\section{Pre-test (PT)}

In this step, it has sought to verify the equivalence between the original version of CPCI in English and the Brazilian versions (Brazilian version 1.1, Brazilian version 1.2, and final version). Data collection for the PT was performed in the waiting rooms of outpatient neurology, orthopedics, physiatrics and rheumatology clinics of a public hospital in the city of Goiânia, GO, Brazil. The study site was chosen considering the characteristics of the pain reported by the users, often of musculoskeletal origin and headache, seeking to obtain a sample similar to the original validation study of $\mathrm{CPCI}^{13}$ and other studies presented in the manual of use of the instrument ${ }^{27}$.

The convenience sample consisted of 59 people with CP, meeting the recommendation of at least 30 people for this step of the study ${ }^{10,28}$. The inclusion criteria to participate in the study were: be 18 years old or older, be in outpatient care, reporting CP (considered as lasting for six months or more in the same site, with minimal episodes every 15 days) ${ }^{33}$. Also, to be able to read and write in Portuguese and to communicate orally independently, no substitute (companion, for example).

Data were collected in the waiting room, between July and October 2016, by three observers. Data collection took place in three steps (PT1, PT2 and PT3):

- PT1: was performed in July 2016, with a sample of 7 participants, with CP, being 5 women and 2 men, aged between 43 and 74 years old, and a variation from 2 to 17 years in relation to the formal study. Two people reported pain from 1 to 5 years, three people complained of pain between 5 to 10 years, and two people 
reported pain for more than 10 years. Seven questionnaires containing socioeconomic and demographic data (sex, age, place of birth, marital status, number of children, number of people living in the household, monthly family income, number of years of study, occupation, and religion) were used and $\mathrm{CP}$ characteristics regarding the time of living with pain; (6 months to 1 year, 1 to 5 years, 5 to 10 years, more than 10 years) and intensity of the pain experience. In addition, the participant responded to the CPCI Brazilian version 1.1 , being oriented to assess the instructions and items of the instrument for clarity and intelligibility. The answer to understanding the instructions and the items could be "I did not understand," "I understood partially" or "Yes, I did." If the answer was "I did not understand," or "I understood partially," the doubts were reported orally and in writing;

- PT2: was performed in September 2016, with a sample of 21 people with CP, 14 women, and 7 men. The participants' ages ranged from 24 to 73 years old $(54.4 \pm 15.3$ years) and the mean number of years of schooling was $6.1 \pm 4.34$ years. Participants assessed only the 12 items of the Brazilian version 1.2 of the CPCI for which there was no consensus among the experts. The questionnaire included data on age, occupation, marital status and number of years of study. Then, after receiving the instructions about the task to be performed, they had contact with the 12 items, in two different translations, being able to choose the one that understood better. For each item, the person could write observations that he/she deemed pertinent;

- PT3: was performed in October 2016, to check the understanding of the Final Brazilian Version of the CPCI. Due to the difficulties of the participants in using the questionnaire in PT1 and PT2, in PT3 they were interviewed. $31 \mathrm{CP}$ users participated, being 20 women and $11 \mathrm{men}$. The mean age was $50.6 \pm 13.0$ years old, 21 were married and the mean of the study years was 6.6 \pm 3.9. The CP more than five years ago was referred by 18 people. During PT3, participants completed socioeconomic and demographic data, pain characteristics and CPCI, were questioned about their doubts, and their responses noted by the observer.

\section{Assessment of the Brazilian Final Version of the Chronic Pain Coping Inventory by experts}

After PT3, the experts assessed the whole process of cross-cultural adaptation through the data and reports produced by the researchers and approved the final Brazilian version of the CPCI. The version thus approved was reviewed by a professional specialized in Portuguese language and then forwarded, with a new back-translation of the final version, to PAR.

The process of cross-cultural adaptation of CPCI to the Brazilian population with $\mathrm{CP}$ is represented in figure 1.

The study was approved by the Ethics Committee of the Federal University of Goiás (UFG), under the opinion no. $1,339,810 / 2015$ respecting the principles of resolution CNS $466 / 12$ and the Declaration of Helsinki.

\section{Statistical analysis}

The analysis of the data generated in the pre-test was done by tabulating the information in the Microsoft Excel 2016 program for MacOS Sierra, and the preliminary reliability analysis was performed in the BM ${ }^{\circ}$ SPSS Statistics version 20.0 statistical package.

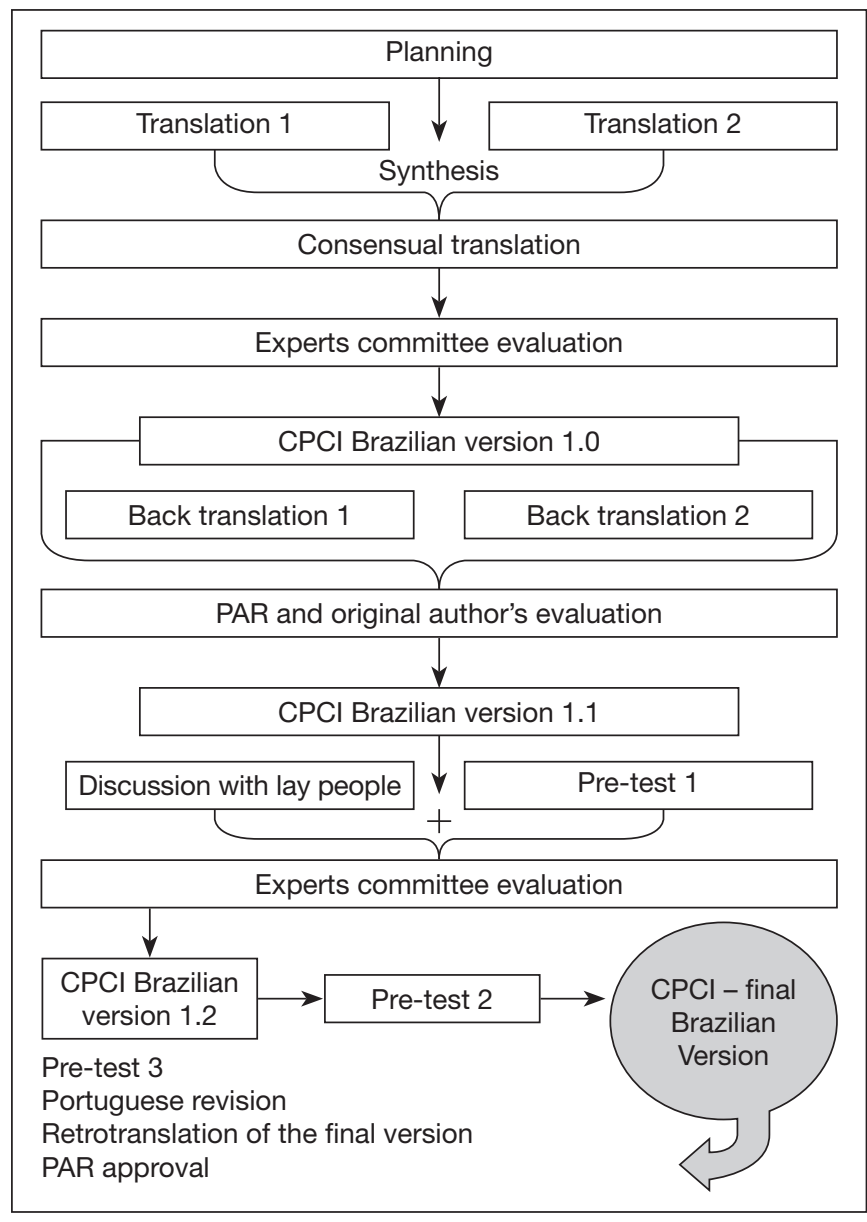

Figure 1. Flowchart of the method used for the cross-cultural adaptation of the Chronic Pain Coping Inventory - Brazilian version - Brazil - 2018 $\mathrm{PAR}=$ Psychological Assessment Resources, Inc.

\section{RESULTS}

The results of the cross-cultural adaptation of the CPCI are presented following the order of the steps taken to perform the research.

\section{Planning}

The PAR granted the authorization for cross-cultural adaptation of the CPCI to the Brazilian population. The CPCI assesses the coping construct using items that deal with protection, rest, requests for help, search for social support, activity rhythm regulation, exercises/stretching, relaxation activities and persistence in tasks ${ }^{27}$.

The search for Brazilian studies on the topic identified only 8 original studies that addressed issues related to coping with $\mathrm{CP}$, and that discussed the CS pointed out by the participants. In total there were three master's dissertations ${ }^{34-36}$, one doctoral thesis ${ }^{7}$ and four articles ${ }^{37-40}$, besides two book chapters ${ }^{41,42}$.

The studies pointed out important contents concerning CS for pain among Brazilians that are not addressed in the CPCI, such as the search for pharmacological treatment and complementary therapies, in addition to religious practices and spirituality. The comparative analysis between the contents of coping addressed in the Brazilian studies and the CPCI subscales can be observed in table 1. 
Table 1. Comparative analysis between contents of coping with pain addressed in Brazilian studies and the subscales of the Chronic Pain Coping Inventory

\begin{tabular}{|c|c|c|c|}
\hline \multicolumn{2}{|c|}{ CS for pain used by Brazilians } & \multicolumn{2}{|r|}{ Subscales of the $\mathrm{CPCl}$ pain coping } \\
\hline Content & Representation of CS & Content & Representation of CS \\
\hline Rest & $\begin{array}{l}\text { Lay in bed, hammock or comfor- } \\
\text { table object, sleep, rest or be } \\
\text { quiet in one place }{ }^{39,40} \text {. }\end{array}$ & Rest & $\begin{array}{l}\text { Items } 5,8,20,43,51,63,70 \\
\text { Rest in comfortable chair or armchair, sleep, lay in bed } \\
\text { or sofa, be quiet in a room. }\end{array}$ \\
\hline Persistence in tasks & $\begin{array}{l}\text { Tolerate pain and continue the } \\
\text { usual activities of life }{ }^{34,35} \text {. }\end{array}$ & Persistence in tasks & $\begin{array}{l}\text { Items } 2,4,30,37,55,69 \text {; go ahead with activities, do } \\
\text { not let pain interfere with them, ignore and do not pay } \\
\text { attention to pain. }\end{array}$ \\
\hline $\begin{array}{l}\text { Coping self-state- } \\
\text { ments }\end{array}$ & $\begin{array}{l}\text { Develop positive thoughts about } \\
\text { the painful experience } e^{7,34} \text {. }\end{array}$ & Coping self-statements & $\begin{array}{l}\text { Items } 11,15,21,23,25,29,32,40,49,53,58 \text {; remem- } \\
\text { ber good things or positive experiences from the past, } \\
\text { have optimistic thoughts. }\end{array}$ \\
\hline $\begin{array}{l}\text { Search for social } \\
\text { support }\end{array}$ & $\begin{array}{l}\text { Engage socially, be with intimate } \\
\text { people }^{37,38} \text {. }\end{array}$ & $\begin{array}{l}\text { Search for social sup- } \\
\text { port }\end{array}$ & $\begin{array}{l}\text { Items } 6,9,17,22,24,48,57,61 \text {; find, talk or spend } \\
\text { time together with friends and family. }\end{array}$ \\
\hline Physical activities & $\begin{array}{l}\text { Go for walking, swim and other } \\
\text { activities }^{34} \text {. }\end{array}$ & $\begin{array}{l}\text { Exercise/ } \\
\text { Stretching }\end{array}$ & $\begin{array}{l}\text { Items } 3,14,19,28,31,35,41,47,56,59,65,66 \text {; exer- } \\
\text { cise in general, or exercise or lengthen specific parts } \\
\text { of the body or the painful region. }\end{array}$ \\
\hline Protection & $\begin{array}{l}\text { Support yourself in goals, avoi- } \\
\text { ding activities }{ }^{40} \text {. }\end{array}$ & Protection & $\begin{array}{l}\text { Items } 12,16,36,38,42,44,50,52,60 \text {; avoid activities, } \\
\text { use support when moving, limp during walking, among } \\
\text { others. }\end{array}$ \\
\hline Not addressed & Not applicable & Asking for help & $\begin{array}{l}\text { Items } 10,27,46,68 \text {; ask for help or assistance in tasks } \\
\text { or activities }\end{array}$ \\
\hline Not addressed & Not applicable & Relaxation & $\begin{array}{l}\text { Items } 1,13,26,33,39,54,64 \text {; breathe slowly and de- } \\
\text { eply, perform self-hypnosis, meditation, among others. }\end{array}$ \\
\hline Not addressed & Not applicable & Rhythm regulation & $\begin{array}{l}\text { Items } 7,18,34,45,62,67 \text {; do activities taking a break, } \\
\text { slowly and continuously. }\end{array}$ \\
\hline Distraction & $\begin{array}{l}\text { Change the focus of pain, divert } \\
\text { attention to try to forget the pain }\end{array}$ & $\begin{array}{l}\text { Addressed in two items } \\
\text { of subscale "Persistence } \\
\text { in tasks" }\end{array}$ & Items 4,37 ; ignore or not pay attention to pain ${ }^{7,34,38,40}$. \\
\hline $\begin{array}{l}\text { Search for pharma- } \\
\text { cological treatment } \\
\text { or complementary } \\
\text { therapies }\end{array}$ & $\begin{array}{l}\text { Medication prescribed by a phy- } \\
\text { sician, self-medication, physical } \\
\text { therapy, acupuncture, local mas- } \\
\text { sages and compresses }{ }^{34,35,39,40} \text {. }\end{array}$ & Not addressed & No items \\
\hline $\begin{array}{l}\text { Religious practices } \\
\text { and spirituality }\end{array}$ & $\begin{array}{l}\text { Practice prayer or other religious } \\
\text { rites have faith in God } 734-36,39\end{array}$ & Not addressed & No items \\
\hline Social isolation & $\begin{array}{l}\text { Be alone, not get involved with } \\
\text { people }{ }^{35,38} \text {. }\end{array}$ & Not addressed & No items \\
\hline
\end{tabular}

$\mathrm{CS}=$ coping strategies; $\mathrm{CPCl}=$ Chronic Pain Coping Inventory.

\section{Translation}

In the analysis of versions $\mathrm{T} 1$ and $\mathrm{T} 2$, the use of different words, although synonymous, was used for the same translation, with the word "cope," where T1 used the word "enfrentar" and T2 translated "lidar."

\section{Synthesis}

In some cases, it was necessary to merge the translation of a sentence, using part suggested by $\mathrm{T} 1$ and part suggested by T2. For example, in item 22 the original version says "I talked to someone close to me," T1 translated as "Falei com alguém intimo," "while T2 proposed "Eu conversei com alguém perto de mim." In the CT the authors chose "Conversei com alguém intimo," using the verb proposed by $\mathrm{T} 2$ and the verbal complement suggested by $\mathrm{T} 1$ since someone who is close is not always intimate.

Similar situations occurred in the CPCI instructions and items 32, 53 and 62. The researchers did not use any of the translations proposed by the translators in items $6,8,13,18,33,35,45,47$,
50, 58 and 68. As an example, one has the instruction that in the original says on the following pages is a list of statements, T1 translated as "segue, nas páginas seguintes, uma lista de declaraçôes", T2 translated as "nas páginas a seguir há uma lista de comandos", the consensual version was "nas páginas a seguir há uma lista de estratégias para enfrentar a dor" After the tabulation of all the translations, there was a reconsideration of the TC only for item 56, where the term "alongar" was used while the most appropriate would be "fortalecer", as pointed out by T1. For the other items and instructions, there were no changes in CT.

\section{A first analysis by the expert committee}

Problems in the congruence between expert assessments (less than $75.0 \%$ agreement) in the semantics of the instructions and in items 26, 33, 35, 50, 57, 61, 63 and 68 were identified. Regarding the cultural and idiomatic equivalences, it was observed the need for changes in items 1, 6, 18, 33, 35, 36, 45, 65 and 68. Problems in 
conceptual equivalence were pointed only to item 33 . The items quoted were modified according to the committee's orientation. As an example, we have item 33 that presented problems at all levels of equivalence assessed. This item in the original says Listened to a relaxation tape to relax, on CT was like "Ouvi uma gravação de áudio para relaxamento." Some comments were made by the committee, as the population does not currently use audio tapes or similar, due to the replacement of digital audio media. Also, the original version specifies that listening to relaxation audio is intended to relax. With these considerations in mind, the item was changed to "Ouvi um áudio de relaxamento para relaxar." At the end of this step, the Brazilian Version 1.0 of the CPCI was obtained.

\section{Back translation}

None of the retro-translators pointed out difficulties in translating the instructions and items of the CPCI-Brazilian version 1.0 into English.

\section{Assessment by PAR and the original author}

The company and author commented on items 3, 7, 13, 22, 27, 34, 36, 38, 55, 57, 62, 63 and 70. After answering the doubts about back translation, it was decided to change the translation of items 3, 34, 36, 57, 63 and 70. After such modifications, the Brazilian version 1.1 of the CPCI was generated.

\section{Pre-test - PT1}

The PT1 participants reported no understanding or partial understanding of the instructions and items 1, 2, 4, 6, 7, 9, 11, 12, $15,17,27,32,34,39,40,42,43,47,50,56$ and 63, totaling 21 items. The item 7 "I was able to do more, just going a little slower and giving myself occasional breaks" which was pointed out as "not understood" by all the participants. However, when asked what they did not understand, they were not able to respond. Important cultural appropriateness was pointed out by one participant, who suggested including the word "hammock" as a rest option in item 43 .

\section{Discussion with lay people}

Among the suggestions made by lay people were important changes in the Brazilian translation of item 7. It starts saying "Fiz mais coisas, quando fiz com calma e fui parando algumas vezes" (original: "I was able to do more by just going a little slower and giving myself occasional breaks"). The lay people suggested adaptations for 17 items different from those already pointed out in PT1 and helped in the comprehension and rewriting of items assessed as difficult to understand by PT1 participants, totaling 38 changes in version 1.1 .

\section{Second assessment by the expert committee}

Of the 38 suggestions for changes made by the lay people, 22 were accepted. Of the remaining 16, four were resolved after discussion between the researchers and 12 items remained with doubts (items 1, 2, $4,7,12,15,27,34,42,43,47$ and 50), being taken to a new assessment in PT2. The Brazilian Version 1.2 of the CPCI was produced.

\section{PT2}

Among the 12 revalued items, five were maintained with the initial translation and seven with the second option (from version 1.2). At the end of this step, the final Brazilian version of the CPCI was obtained.

\section{Final assessment}

PT3 started after the Portuguese revision. There were no doubts as to the understanding of the items. The expert committee and the PAR assessed the last version of the instrument, as well as the data generated by the pre-test and the back-translation, giving a favorable opinion for the application in the Brazilian population. A sample of three items of the instrument as follows (Figure 2).

\section{Instructions}

The following pages present a list of pain coping strategies. Please, check how many days you used each of them, at least once a day, last week, to cope with your pain.

(Note: you might have used one of these coping strategies on the days that you hadn't pain to prevent or to minimize in future situations. Please, check the number of days that you have used each strategy FOR THE PAIN, regardless of having pain or not at that moment). Read each statement and circle the number of days that you adopted this strategy last week.

Example: I rested as much as I could

1284567

If you check the wrong option, or if you want to change it, DO NOT ERASE. Instead, put an X on the answer you want to change and then make a circle on the right answer.

\begin{tabular}{|c|c|c|c|c|c|c|c|c|}
\hline \multicolumn{2}{|r|}{ Example: I rested as much as I could } & 12( & C & 4 & & 5 & 6 & 7) \\
\hline $\mathrm{N}^{\circ}$ & Pain coping strategies & $\begin{array}{l}\text { Number of days } \\
\text { the pain coping }\end{array}$ & $\begin{array}{l}\text { duri } \\
\text { strat }\end{array}$ & $\begin{array}{l}\text { ing } 1 \\
\text { tegy }\end{array}$ & & & & that you used \\
\hline 7 & I was able to do more by just going a little slower and giving myself occasional breaks. & & 12 & 3 & 4 & 5 & 6 & 7 \\
\hline 22 & I talked to someone close to me. & & 12 & 3 & 4 & 5 & 6 & 7 \\
\hline 33 & Listened to a relaxation tape to relax. & & 12 & 23 & 4 & 5 & 6 & 7 \\
\hline
\end{tabular}

Figure 2. Chronic Pain Coping Inventory - Brazilian version ${ }^{1}$ : sample of 3 items

*"Adapted and reproduced with permission of the Publisher, Psychological Assessment Resources, Inc. (PAR), 16204 North Florida Avenue, Lutz, Florida 33549, from the $\mathrm{CPCl}$ authored by Mark P. Jensen, PhD, Judith A. Turner, PhD, Joan M. Romano, PhD and Warren R. Nielson, PhD, Copyright 1995, 2008 by PAR. Reproduction without the express permission of PAR is prohibited". The use of CPCl-Brazilian Version in research and clinical practice may be performed after authorization with PAR (https://www.parinc.com). 


\section{Preliminary reliability psychometric analysis:}

The reliability of the CPCI-Brazilian Version was adequate for some subscales and not for others. The value for the disease-focused CS domain was 0.82 . In the subscales belonging to this domain, the value for reliability was 0.45 for "rest," 0.73 for the "protection" subscale and 0.82 for "asking for help." In the CS domain focused on well-being, the value was 0.85 . The subscale of "social support" obtained alpha of 0.84 , "coping self-statements" 0.79 , that of "rhythm regulation" 0.65 , "exercises/stretching" 0.95, "relaxation" 0.54 and "persistence in tasks" 0.47.

\section{DISCUSSION}

The CPCI was adapted for use in patients with CP in Brazil, considering the cultural nuances of the country. During the process, differences were observed in some of the representations of the concepts regarding coping with pain in the Brazilian population when compared to the coping behaviors assessed by the CPCI. The analysis of the representation of the "coping with pain" construct in the Brazilian population showed that behaviors such as resting, persisting in tasks, performing coping self-statements, performing physical activities, exercises or stretching, and protective behaviors are common characteristics among CS for pain in Brazilians and those investigated by $\mathrm{CPCI}^{7,34,35,37-40}$.

The cross-cultural adaptation of the instrument allowed the inclusion of the "hammock" as an object used to rest, together with a chair and armchair that were already in the original instrument (item 43). A hammock is an object typically used in some regions of Brazil, since the time of colonization, thanks to the influence of the indigenous culture. The representation of the hammock as an object of rest appeared both in the analysis of Brazilian literature on coping with pain ${ }^{39}$ and also in pre-test 1 of cross-cultural adaptation.

Some considerations should be made about the representation of physical activities such as CS for pain among Brazilians and the CPCI exercise/stretching subscale.

Brazilian studies point to the use of CS for pain through various physical activities, especially walking, swimming and aqua aerobics ${ }^{34}$. It is observed that CPCI items that refer to exercises and stretching have criteria regarding the amount of exercise performed. Stretching, for example, should be for a minimum of 10 seconds, muscle strengthening exercises should be minimally 1 minute in duration, and aerobic activities should last at least 15 minutes ${ }^{27}$. Exercising and increasing the level of physical activity is an important tool for pain management programs, and at this point, it is worth remembering that CPCI was developed in the context of a multidisciplinary program to treat this experience ${ }^{27}$. Although any activity is considered for the purpose of CS of pain, including household chores such as gardening, cooking, among others, these should not initially be the main objective of positive contingency reinforcement in the treatment because they are not quantifiable in terms of rhythm, periodicity, and physical tolerance. On the other hand, standardized exercises such as walking, pedaling on a fixed bicycle, climbing and descending steps and gymnastics for specific muscle groups can be quantified and determined regarding time and rhythm, and are the most indicated for programs of pain treatment ${ }^{43}$. In addition, when acquiring tolerance to the mentioned physical activities, the trend is that other more common activities are also improved, such as domestic work ${ }^{43}$.

Thus, despite the fact that for a Brazilian version of a CS pain measuring instrument it is desirable to include items that address several physical activities, such a measure should be considered with caution. Generalizing activities without measuring their rhythm could lead to measure a CS that had no impact on the functional adjustment of the individual, not corroborating with the theory at hand of coping with pain ${ }^{12}$. For example, to measure the practice of walking, it would be necessary to specify the number of steps or the distance traveled without breaks and at the same rhythm, which may have a variation in the tolerance of activity among people. Therefore, measuring stretching, practicing aerobic exercise for at least 15 minutes, and strengthening exercises of specific muscle groups may be sufficient, since they generally encompass the activities performed when practicing swimming, aqua aerobics, and others, assessing, even so, the exercise as a subdomain of the construct of coping with pain.

The CPCI subdomains of "persistence in tasks," " coping self-statements," "search for social support" and "protection" present representations of concepts equivalent to those of Brazilian culture, as can be observed in table 1, and are therefore relevant to the investigation of pain CS among Brazilians.

Despite the similarities noted above, the CPCI subscales "asking for help," "relaxation" and "rhythm regulation" did not appear as CS content for pain in publications of studies conducted among Brazilians. However, this may have occurred due to the type of guiding question and/or qualitative approach performed by the studies that did not investigate, for the most part, CS specifics for pain, but rather behaviors for its management. In addition, people might not know that regulating the rhythm of their activities, doing them taking a break, is an action to cope with pain, and therefore did not quote such behavior during the studies. In fact, in clinical practice, it is observed that many people who suffer from pain change the rhythm of their activities in an attempt to maintain their functions in daily life, ask for assistance from people in performing ordinary activities and try to relax to relieve the pain. Despite these observations, it is not possible to state, without further investigation, whether people attribute these behaviors to ways of coping with pain or whether they are seen as inevitable consequences of painful experience.

Regarding the relaxation subscale, during the assessment phase of CPCI Brazilian version 1.0 and its back translations by PAR, the researchers questioned about item 54 that deals with the use of self-hypnosis for relaxation since this practice is unknown by most Brazilians. Perhaps the same occurs in the population of Spain, considering that in the analysis of psychometric properties of this item in the Spanish version ${ }^{19}$ there was a suggestion to suppress this item. In the Italian CPCI validation study, there were also problems in the relaxation subscale, which the authors attributed to a possible difference in cultural concepts about relaxation ${ }^{25}$.

After discussion with PAR, it was decided to maintain the item until confirmation of the psychometric property of the subscale and item. Also, meta-analyses indicate the use of hypnosis as a 
tool with moderate efficacy in multidisciplinary treatment ${ }^{44,45}$. In addition to self-hypnosis, CPCI addresses guided imagery, muscle relaxation, listening to specific songs or audios of relaxation, meditation, and slow, deep breathing like CS that can be pointed out by the Brazilian as relaxation tools.

It is observed, therefore, that the CPCI covers the main aspects of coping with pain pointed out in the Brazilian studies on the topic. However, future research needs to investigate whether the absence of items related to spiritual and religious practices, drug products use (self-medication or prescription), and complementary therapies may interfere with the measure of the construct of coping among Brazilians, since CPCI does not cover such content.

The use of spiritual or religious practices such as CS, for example, is already a well-established topic in national and international literature ${ }^{46,47}$, being considered as religious behavior, spirituality or faith in the sacred and which are directed towards the solution, prevention or alleviation of problems and emotional consequences resulting from stressful situations ${ }^{46}$. Nevertheless, many authors differentiate spirituality from religiosity, attributing to the former the concept of searching for the meaning of life and transcendental experiences, and to the latter a more institutionalized and collective doctrinal practice ${ }^{46-48}$. It is worth emphasizing that conceptual studies about these constructs are directed not to separate the concepts of religiosity and spirituality since these are interdependent and related ${ }^{46-48}$.

The use of religious/spiritual CS improves the work of the hippocampus and defense memory to stress, in addition to increasing the number of serotonergic receptors in the brain, which results in regulation of $\operatorname{mood}^{49}$. Thus, some of the religious behaviors such as seeking social support in the religious community, praying for personal and other well-being, seeking help and comfort in religious literature, meditating, solving problems with the collaboration of the sacred entity, among others, may be associated with better standards of well-being and health ${ }^{47,50-52}$.

On the other hand, religious CS can also trigger dysfunctions such as depression and anxiety if they include transfer behaviors, to a higher entity, responsibility for their own actions, delegation to the sacred object to problem-solving, or redefining the stressor as punishment divine or evil forces, among others ${ }^{47,53}$.

Brazilians show high use of CS focused on religious practices. A study conducted in eight long-stay institutions in a capital of the Mid-West region of Brazil showed that $78.20 \%$ of the elderly used CS for CP focused on religious practices. Praying (88.20\%), expecting a miracle to happen $(71.10 \%)$ and adherence to the faith to overcome pain (93.20\%). Moreover, $100 \%$ of those surveyed reported having practiced religion more since they experienced pain, praying $(\mathrm{p}=0.02)$ and adherence to the faith $(\mathrm{p}=0.01)$ were associated with pain intensity ${ }^{36}$. Already in another Brazilian study, researchers observed that religious practice and fanciful thoughts were the CS with the highest average use among women with central $\mathrm{CP}$ after encephalic vascular accident ${ }^{54}$ and that praying is the most used CS among people with fibromyalgia ${ }^{7}$.

Despite the methodological limitations of the mentioned Brazilian studies, mainly because they were performed with small samples, it is observed that they indicate the importance that the religiosity has in the coping with $\mathrm{CP}$ among Brazilians. This fact converges with the content analysis performed in this study on the representation of coping with $\mathrm{CP}$ in Brazil. It was also observed that the CPCI does not assess these aspects. However, this should not be a limiting factor for its use, since most of its content shows relevance to the understanding of the construct among Brazilians. It is suggested, therefore, that the initial studies with CPCI add the use of instruments that measure religious coping, such as the Religious-Spiritual Coping Scale (CRE, the Brazilian version of RCOPE) ${ }^{55}$. Thus, after a greater maturation of the Brazilian research on the coping with pain, a bank of items on all contents of importance for the assessment of this construct could be elaborated.

Regarding the investigation of CS regarding pharmacological treatments and complementary therapies, it is important to observe that the first version of CPCI had an open item in which the respondent could indicate the treatments used ${ }^{13}$. However, during the review of the instrument in 2008, this item was withdrawn with the justifications that it did not belong to any of the CPCI subscales and that requiring open response made it difficult to tabulate the data ${ }^{27}$. The investigation of such characteristics of pain CS in the Brazilian population depends on the development of new items for the CPCI.

In the preliminary investigation of the reliability of the subscales of the CPCI Brazilian version, it was observed an inadequacy in the values obtained for the rest subscales $(\alpha=0.45)$, rhythm regulation $(\alpha=0.65)$, relaxation $(\alpha=0.54)$ and persistence in tasks $(\alpha=0.47)$. In fact, some studies have found insufficient reliability for the relaxation subscales $(\alpha=0.69-0.51)^{26,56}$, protection $(\alpha=0.64)^{56}$, persistence in tasks $(\alpha=0.69-0.62)^{22,56}$, coping self-statements $(\alpha=0.69)^{58}$, but only when investigated in the reduced CPCI version of 42 items. It is believed that these values in this study are due to the size of the sample to which the instrument was applied since the objective was the cross-cultural adaptation and not the assessment of the psychometric characteristics. Nevertheless, the CPCI Brazilian version evidences reliability in the protection subscales, asking for help, search for social support, coping self-statements and exercises/stretching. One of the limitations of the CPCI is the size of the instrument (70 items) that can make it unfeasible to use in clinical practice routinely due to the time required for the application (approximately 15 minutes) and the patient's own fatigue answer the questions. However, reduced versions of 42, 16 and 8 items have been developed that, although they impose fragility on the instrument, remain valid, allowing the tracking of the coping in survey contexts or in the general clinical practice ${ }^{57,58}$. For future reductions of the CPCI - Brazilian version, new research is needed in its complete form to trace the relevance of each item to the measure of the construct and its dimensions among Brazilians. It is also necessary to determine the psychometric properties of CPCI - Brazilian version and verification of the need for inclusion of items related to religious practices and use of pharmacological methods and complementary therapies such as CS from $\mathrm{CP}$

\section{ACKNOWLEDGMENTS}

Thanks to the Foundation for Research Support of Goiás State (FAPEG) for the doctoral scholarship granted to the main author of 
the study, making this research feasible. To the professors Dr. Maria Márcia Bachion and Dr. Cibele Andrucioli de Mattos Pimenta for the revision of the CPCI- Brazilian version and suggestions.

\section{REFERENCES}

1. Lazarus R, Folkman S. Stress, appraisal and coping. New York: Springer US; 1984. 437p

2. Kato T. Frequently used coping scales: a meta-analysis. Stress Health. 2015;31(4):315-23.

3. Brown GK, Nicassio PM. Development of a questionnaire for the assessment of active and passive coping strategies in chronic pain patients. Pain. 1987;31(1):53-64.

4. Reid GJ, Gilbert CA, McGrath PJ. The Pain Coping Questionnaire: preliminary validation. Pain. 1998;76(1-2):83-96.

5. Kraaimaat FW, Evers AW. Pain-coping strategies in chronic pain patients: psychometric characteristics of the pain-coping inventory (PCI). Int J Behav Med. 2003;10(4):343-63.

6. Rosenstiel AK, Keefe FJ. The use of coping strategies in chronic low back pain patients: relationship to patient characteristics and current adjustment. Pain.1983;17(1):33-44.

7. Portnoi A. Stress e Coping: grupos operativos em doentes com síndrome de fibromialgia. Universidade de Sáo Paulo; 1999.

8. Beaton DE, Bombardier C, Guillemin F, Ferraz MB. Guidelines for the process of cross-cultural adaptation of self-report measures. Spine. 2000;25(24):3186-91.

9. Epstein J, Santo RM, Guillemin F. A review of guidelines for cross-cultural adaptation of questionnaires could not bring out a consensus. J Clin Epidemiol. 2015;68(4):435-41.

10. Guillemin F, Bombardier C, Beaton D. Cross-cultural adaptation of health-related quality of life measures: literature review and proposed guidelines. J Clin Épidemiology. 1993;46(12):1417-32.

11. Beck JS. Terapia Cognitivo-Comportamental: teoria e prática. $2^{\text {a }}$ ed. Porto Alegre: Artmed; 2013. 413p.

12. Jensen MP, Turner JA, Romano JM, Karoly P. Coping with chronic pain: a critical review of the literature. Pain. 1991;47(3):249-83.

13. Jensen MP, Turner JA, Romano JM, Strom SE. The Chronic Pain Coping Inventory: development and preliminary validation. Pain. 1995;60(2):203-16.

14. Truchon M, Côté D. Predictive validity of the Chronic Pain Coping Inventory in subacute low back pain. Pain. 2005;116(3):205-12.

15. Truchon M, Côté D, Irachabal S, Cote D, Irachabal S. The Chronic Pain Coping Inventory: confirmatory factor analysis of the French version. BMC Musculoskelet Disord. 2006;7:13.

16. Hadjistavropoulos HD, MacLeod FK, Asmundson GJ. Validation of the Chronic Pain Coping Inventory. Pain. 1999;80(3):471-81.

17. Nielson WR, Jensen MP, Hill ML. An activity pacing scale for the chronic pain coping inventory: development in a sample of patients with fibromyalgia syndrome. Pain. 2001;89(2-3):111-5.

18. Ektor-Andersen J, Ørbæk P, Isacsson SO. Behaviour-focused pain coping: Consistency and convergence to work capability of the Swedish version of the chronic pain coping inventory. J Rehabil Med. 2002;34(1):33-9.

19. Garcia-Campayo J, Pascual A, Alda M, Gonzalez Ramirez MT. Coping with fibromialgia: usefulness of the Chronic Pain Coping Inventory-42. Pain. 2007;132(Suppl 1):S68-76

20. Chang HY, Yang YL, Jensen MP, Lee CN, Lai YH. The experience of and coping with lumbopelvic pain among pregnant women in Taiwan. Pain Med. 2011;12(6):846-53.

21. Cheng S, Cheung C, Ng V, Lim H, Leung K, Chan A, et al. Factor structure, psychometric properties, and correlates of revised Chinese version of Chronic Pain Coping Inventory among chronic pain patients in Hong Kong. J Pain Symptom Control Palliat Care. 2014;10(1):1-7.

22. Wong WS, Jensen MP, Mak KH, Tam BK, Fielding R. Preliminary psychometric properties of the Chinese version of the Chronic Pain Coping Inventory (ChCPCI) in a Hong Kong Chinese population. J Pain. 2010;11(7):672-80.

23. Ko YM, Park WB, Lim JY. Cross-cultural adaptation and clinimetric property of Korean version of the Chronic Pain Coping Inventory- 42 in patients with chronic low back pain. Spine. 2010;35(6):666-71.

24. Ferreira-Valente MA, Pais Ribeiro JL, Jensen MP, Almeida R. Coping with Chronic Musculoskeletal Pain in Portugal and in the United States: A Cross-Cultural Study. Pain Med. 2011;12(10):1470-80.

25. Monticone M, Ferrante S, Giorgi I, Galandra C, Rocca B, Foti C. Development of the Italian version of the 42-item Chronic Pain Coping Inventory, CPCI-I: Cross-cultural adaptation, factor analysis, reliability and validity. Qual Life Res. 2013;22(6):1459-65.

26. Misterska E, Jankowski R, Głowacki M. Psychometric properties of the Polish language version of the chronic pain coping inventory- 42 for patients treated surgically due to herniated lumbar discs and spondylotic changes. Med Sci Monit. 2014;20:789-801.
27. Jensen M, Turner J, Romano J, WR N. Chronic Pain Coping Inventory: Professional Manual. 1a ed. Lutz: Psychological Assessment Resources Inc; 2008.

28. Wild D, Grove A, Martin M, Eremenco S, McElroy S, Verjee-Lorenz A, et al. Principles of good practice for the translation and cultural adaptation process for patient-reported outcomes (PRO) measures: report of the ISPOR Task Force for Translation and Cultural Adaptation. Value Health. 2005;8(2):94-104.

29. Borsa JC, Damásio BF, Bandeira DR. Adaptaçáo e validaçăo de instrumentos psicológicos entre culturas: algumas consideraçōes. Paidéia. 2012. 423-32p.

30. Garyfallos G, Karastergiou A, Adamopoulou A, Moutzoukis C, Alagiozidou E, Mala $\mathrm{D}$, et al. Greek version of the General Health Questionnaire: accuracy of translation and validity. Acta Psychiatr Scand. 1991;84(4):371-8.

31. Herdman M, Fox-Rushby J, Badia X. "Equivalence" and the translation and adaptation of health-related quality of life questionnaires. Qual Life Res. 1997;6(3):237-47.

32. Soeken W. Validity of Measures. In: Waltz C, Strickland O, Lenz E, (Org.). Measurement in nursing and health research. 3rd ed. New York: Springer Publishing Company; 2005. 154-89p.

33. Merskey H, Bogduk N. Classification of chronic pain. In: Classification of Chronic Pain. second. Seattle: IASP Press; 1994. 1p.

34. Araújo P. Percepçáo de pessoas acerca da dor crônica e práticas utilizadas no seu controle. Escola Bahiana de Medicina e Saúde Pública; 2016.

35. Nogueira M. Gênero: representação cognitiva e enfrentamento da dor central decorrente de acidente vascular encefálico. Universidade de São Paulo; 2010.

36. Souza LAF. Análise do enfrentamento da dor crônica entre idosos de instituiçôes de longa permanência de uma metrópole goiana, Brasil. Universidade Federal de Goiás; 2013.

37. Câmara SG, Carlotto MS. Coping e gênero em adolescentes. Psicologia em Estudo. 2007. 87-93p

38. Silva DS, Rocha EP, Vandenberghe L. Tratamento psicológico em grupo para dor crônica. Temas em Psicologia. 2010. 335-43p.

39. Arcanjo GN, Silva RM, Nations MK. Saber popular sobre dores nas costas em mulheres nordestinas (Monografia). 2007. 389-97p.

40. Nogueira M, Casetto S. Gênero e enfrentamento da dor. Psicol Rev. 2006;15(2):161-76

41. Nogueira M. Gênero e enfrentamento da dor central. In: A psicologia da dor. $1^{\text {a }}$ ed. São Paulo: Guanabara Koogan; 2014. 147-57p.

42. Portnoi A, Nogueira M, Maeda F. O enfrentamento da dor crônica. In: Alves Neto O. (Org.). Dor: Princípios e Práticas. 1a ed. Porto Alegre: Artmed; 2008. 294-301p.

43. Fordyce WE, Jensen MP. Exercise and the increase in activity level. In: Main CJ, Keefe FJ, Jensen MP, Vlaeyen JWS, Vowles KE, (Org.) Fordyce's behavioural methods for chronic pain and illness: republished with invited commentaries. Philadelphia, USA: International Association for the Study of Pain (IASP); 2015. 451p.

44. Montgomery GH, DuHamel KN, Redd WH. A meta-analysis of hypnotically induced analgesia: how effective is hypnosis? Int J Clin Exp Hypn. 2000;48(2):138-53.

45. Adachi T, Fujino H, Nakae A, Mashimo T, Sasaki J. A meta-analysis of hypnosis for chronic pain problems: a comparison between hypnosis, standard care, and other psychological interventions. Int J Clin Exp Hypn. 2014;62(1):1-28.

46. Pargament KI. The psychology of religion and coping: theory, research, practice. New York: Guilford Press; $1997.548 \mathrm{p}$.

47. Panzini RG, Bandeira DR. Coping (enfrentamento) religioso/espiritual. Rev Psiq Clín. 2007;34(Suppl 1):126-35.

48. Hill PC, Pargament KII, Hood RW, McCullough J. ME, Swyers JP, Larson DB, et al Conceptualizing religion and spirituality: points of commonality, points of departure. J Theory Soc Behav. 2000;30(1):51-77.

49. Seybold KS. Physiological Mechanisms Involved in Religiosity/Spirituality and Health. J Behav Med. 2007;30(4):303-9.

50. Bush EG, Rye MS, Brant CR, Emery E, Pargament KI, Riessinger CA. Religious coping with chronic pain. Appl Psychophysiol Biofeedback. 1999;24(4):249-60.

51. Peres MF, Lucchetti G. Coping strategies in chronic pain. Curr Pain Headache Rep. 2010;14(5):331-8.

52. Wachholtz AB, Pearce MJ, Koenig H. Exploring the relationship between spirituality, coping, and pain. J Behav Med. 2007;30(4):311-8.

53. Peres AM, Ciampone MH. Gerência e competências gerais do enfermeiro. Texto Contexto Enferm 2006;15(3):492-9.

54. Nogueira M, Teixeira MJ. Central pain due to stroke: cognitive representation and coping according to gender. Arq Neuropsiquiatr. 2012;70(2):125-8.

55. Panzini RG, Bandeira DR. Escala de coping religioso-espiritual (Escala CRE): elaboração e validação de construto. Psicologia em Estudo, Maringá. 2005;10(3):507-16.

56. Ersek M, Turner JA, Kemp CA. Use of the chronic pain coping inventory to assess older adults' pain coping strategies. J Pain. 2006;7(11):833-42.

57. Jensen MP, Keefe FJ, Lefebvre JC, Romano JM, Turner JA. One- and two-item measures of pain beliefs and coping strategies. Pain. 2003;104(3):453-69.

58. Romano JM, Jensen MP, Turner JA. The chronic pain coping inventory-42: Reliability and validity. Pain. 2003;104(1-2):65-73. 